\title{
Edge Port Excited Metamaterial Based Patch Antennas for 5G Application
}

\author{
Pandharinath R. Satarkar ${ }^{1,2}$, Rajesh B. Lohani1,2 \\ ${ }^{1}$ Department of Electronics \& Telecommunication, Goa College of Engineering, Goa University, Farmagudi, Goa, India \\ ${ }^{2}$ Government of Goa, Farmagudi, Goa, India \\ Email: psatarkar10@gmail.com,rblohani@gec.ac.in
}

How to cite this paper: Satarkar, P.R. and Lohani, R.B. (2021) Edge Port Excited Metamaterial Based Patch Antennas for 5G Application. Communications and Network, 13, 111-129.

https://doi.org/10.4236/cn.2021.133009

Received: July 9, 2021

Accepted: August 28, 2021

Published: August 31, 2021

Copyright $\odot 2021$ by author(s) and Scientific Research Publishing Inc. This work is licensed under the Creative Commons Attribution International License (CC BY 4.0).

http://creativecommons.org/licenses/by/4.0/

\section{(c) (i) Open Access}

\begin{abstract}
Microstrip Patch Antenna is a narrowband antenna fabricated by etching the antenna element pattern in metal trace of elements like copper bonded to an insulating dielectric substrate with a continuous metal layer on the opposite side of the substrate which forms a ground plane. Electromagnetic Metamaterial is an artificial material that is made up of different types of structural designs on dielectric substrates. In this paper, a broad and elite investigation is being carried out by designing and simulating a single negative metamaterial cell comprising a square split ring resonator. This metamaterial cell depicts negative values of permeability for a specific range of frequencies. These cells show exceptionally great applications in the design of microstrip patch antenna. The substrate of the microstrip patch antenna with a ground plane is loaded with a square split-ring resonator, Conventional and proposed patch antennas are simulated, analyzed, and reported for performance comparison of its parameters. The proposed edge port feed metamaterial based Rectangular microstrip patch antenna and Circular patch antenna designed at $26 \mathrm{GHz}$ resonance frequency useful for $5 \mathrm{G}$ applications. Both antennas are designed on RT Duroid 5880 Substrate with 2.2, dielectric constants. The parameters such as bandwidth, gain and return loss of metamaterial loaded rectangular microstrip patch antenna and Circular patch antenna increases considerably compared to conventional antennas. Comparing parameters of both antennas, the performance of the rectangular microstrip patch antenna is found to be better than circular patch antenna.
\end{abstract}

\section{Keywords}

Microstrip, Substrate, RT Duroid, FEKO, Polarization, Electromagnetics, Antenna, Metamaterial 


\section{Introduction}

Microstrip patch antennas are being widely used for small wireless communication aerospace applications WiMAX, WLAN, and 5G applications. This antenna is compact shapes like rectangular, circular, and triangular. A patch antenna is designed on a dielectric substrate such as RT duroid 5880 with dielectric constant 2.2. The thickness of this dielectric substrate is $0.5 \mathrm{~mm}$. Lightweight and easy to design and fabricate [1] [2]. It can be designed in different this dielectric substrate is $0.5 \mathrm{~mm}$. If we use a substrate of higher thickness efficiency can be increased, however, as the height increases, surface waves are introduced which usually are not desirable because they extract power from the total available for direct radiation (space waves). The surface waves travel within the substrate and they are scattered at bends and surface discontinuities, such as the truncation of the dielectric and ground plane, and degrade the antenna pattern and polarization characteristics. Surface waves can be eliminated, while maintaining large bandwidths, by using metamaterials. If the impedance of the antenna does not match with the impedance of a transmission line then there will be a reflection of the signals and it causes high return loss and which will lead to bad communication. To avoid the problem of return loss, the antenna impedance should be matched with the transmission line impedance. To increase the bandwidth of patch antenna arrays can be used. Bandwidth also can be increased by loading metamaterial on a microstrip patch antenna. The authors have designed and simulated an Edge port-fed rectangular patch antenna and Circular patch antenna for a 5G application using FEKO software. RT duroid 5880 a high-frequency laminate is used for designing a Patch antenna. The metamaterial-based Rectangular microstrip patch antenna (RMPA) is simulated and bandwidth, return loss, and gain are measured. Optimization is done by using FEKO software. $\mathrm{Mu}$ (single) negative metamaterial cells are loaded on the ground plane of the rectangular and circular patch antenna. A significant improvement in patch antenna parameters has been observed [3] [4] [5] [6].

\section{Metamaterials}

\subsection{Double Negative or Left-Handed Metamaterials}

They are artificial materials that show negative permittivity permeability and refractive index. These parameters are not found in natural materials. Due to the negative refractive index, phase velocities, as well as group velocity of electromagnetic waves are opposite to each other, and opposite energy flow is observed. Metamaterials having either permittivity or permeability negative are called single negative metamaterials. Equations (1) and (2) are two of Maxwell's equations given to understand metamaterial. $\mu_{r}$ and $\varepsilon_{r}$ are relative permeability and permittivity respectively.

$$
\nabla \times E=-\mu_{0} \mu_{r} \frac{\partial H}{\partial t}
$$




$$
\nabla \times H=-\varepsilon_{0} \varepsilon_{r} \frac{\partial E}{\partial t}
$$

where $\varepsilon_{r}$ and $\mu_{r}$ are relative permittivity and permeability respectively and Equation (3) is a wave equation derived from the above equation.

$$
\nabla^{2} E=-\varepsilon_{0} \mu_{0} \varepsilon_{r} \mu_{r} \frac{\partial^{2} E}{\partial t^{2}}
$$

If $\varepsilon_{r}$ and $\mu_{r}$ are considered as real numbers, then one can observe that the wave equation does not change when signs of $\varepsilon_{r}$ and $\mu_{r}$ are simultaneously changed. The Drude Lorentz model describes the material properties in classical electromagnetic. The effective permittivity and permeability are given in Equations (4) and (5) respectively.

$$
\begin{gathered}
\varepsilon_{e f f}=1-\frac{f_{p}^{2}}{f^{2}-j \gamma f} \\
\mu_{e f f}=1-\frac{f_{m p}^{2} f_{0}^{2}}{f^{2}-f_{0}^{2}-j \gamma f}
\end{gathered}
$$

The plasma frequency is denoted by $f_{p}$ and $f_{m p}$ in Equations (5) and (6) respectively, $f_{0}$ is the resonance frequency, $f$ is the frequency of the signal, and damping factor $\gamma$ which is in connection to material losses. These equations can show microwave range to optical range properties of materials [7] [8].

The SSRR Structure is designed using MATLAB code. In this way, a metal surface is obtained, as shown in Figure 1. The equivalent circuit for SSRR is presented in Figure 2. The inductance of the tank circuit model, Ls is calculated

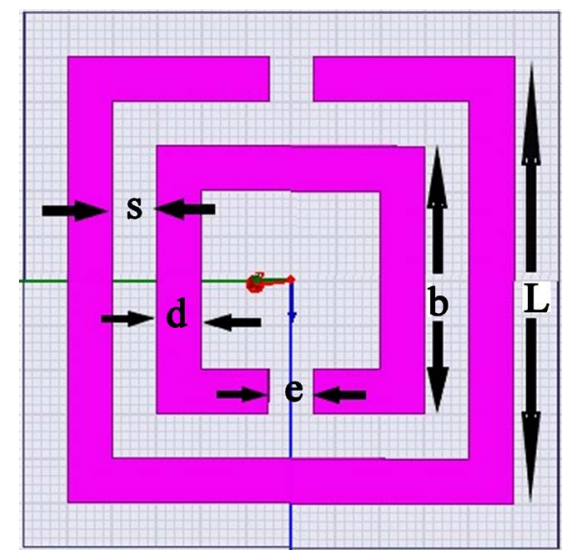

Figure 1. Square split-ring resonators (SSRR).

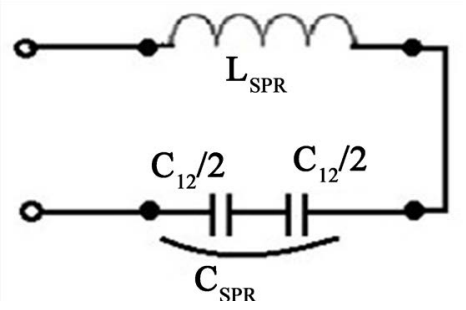

Figure 2. Equivalent circuit for SSRR cell. 
by assuming the uniform current throughout the loop. The capacitance of the tank circuit is assumed to be the parallel equivalent of the capacitances in each pair of adjacent loops. The SSRR creates a negative $\mu$ near resonance frequency. The magnetic field vector of the incident plane wave is perpendicular to the SSRR, which gives rise to the induced currents resulting in an effective magnetic moment that eventually will yield the negative permeability. The metamaterial supported backward-wave propagation only for the magnetic field directed perpendicular to the SSRR. We have presented the retrieval of parameters of a metamaterial cell using MATLAB to verify the mu negativity of a cell. The inherent feature of CST is used to invoke the CST platform through MATLAB script file [9] [10].

\subsection{Design of Square Split Ring Resonator Cell}

The SSRR is designed on RT Duroid 5880 substrate with a permittivity value equal to 2.2 and thickness equal to $0.5 \mathrm{~mm}$. The dimensions of $1 \times 1 \mathrm{~mm}$ SSRR cell are, $L=0.9 \mathrm{~mm}, b=0.68 \mathrm{~mm}, s=0.05 \mathrm{~mm}, d=0.06 \mathrm{~mm}$, and $e=0.13 \mathrm{~mm}$. The resonance frequency is inversely proportional to the dimensions of the metamaterial cell and directly proportional to strip width and slit width. $S_{11}$ and $S_{21}$ of SSRR cell are depicted in Figure 3. The lowest magnitude of $S_{11}$ indicates that the cell resonates at $26 \mathrm{GHz}$ frequency. The Magnitude of $S_{11}$ and $S_{21}$ at $26 \mathrm{GHz}$ frequency is 0.2 and 0.78 respectively, which shows that return loss is low at the resonance frequency. Both $\mathrm{S}$ parameters are important to calculate the epsilon and $\mathrm{mu}$ of the cell. Frequency v/s real and imaginary values of mu are plotted using MATLAB software.

RT/duroid 5880 glass microfiber reinforced PTFE composites are designed for high frequency microstrip circuit applications. The dielectric constant of RT/ duroid 5880 laminates is less (2.2) likely to demonstrate a dielectric breakdown at high frequency. It is uniform over a wide frequency range. As dielectric constant decreases bandwidth increases. Its low dissipation factor (0.0009) extends

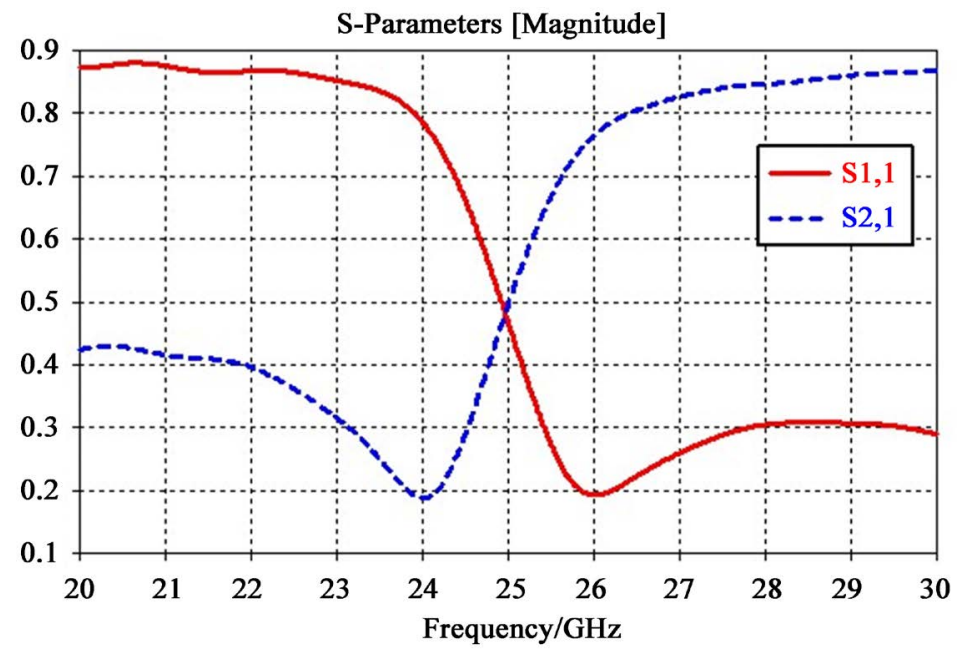

Figure 3. $S_{11}$ and $S_{21}$ of SSRR cell. 
the usefulness of RT/duroid 5880 laminates to Ku-band and above. RT/duroid 5880 laminates are easily cut, sheared and machined to shape. They are resistant to all solvents and reagents, hot or cold, normally used in etching printed circuits or in plating edges and holes.

\subsection{Parameters of SSRR Metamaterial Cell}

$S_{11}$ and $S_{21}$ of SSRR cell are depicted in Figure 3. The lowest magnitude of $S_{11}$ indicates that the cell resonates at $26 \mathrm{GHz}$ frequency. The Magnitude of $S_{11}$ and $S_{21}$ at $26 \mathrm{GHz}$ frequency is 0.2 and 0.78 respectively, which shows that return loss is low at the resonance frequency. Both $S$ parameters are important to calculate the epsilon and mu of the cell. Frequency v/s real and imaginary values of mu are plotted using MATLAB software.

Real and imaginary number of Mu of SSRR is shown in Figure 4. The negative mu appears in the frequencies between $24.8 \mathrm{GHz}$ to $4 \mathrm{GHz}$. Therefore the antenna on metamaterial must be designed to operate within the range of frequencies. Hence, in this project, we considered a resonance frequency of 26 $\mathrm{GHz}$. which is one of the frequency bands used for $5 \mathrm{G}$ applications.

\subsection{Method to Find Parameters of Metamaterial Cell of Complex Structure}

It is sometimes difficult to calculate the effective parameters of certain metamaterials, due to the complex structure. In such cases, parameters can be found out from numerical simulations. First, we have to find out the transmission and reflection coefficient of the cell based on numerical algorithms, such as (FDTD) and Finite Element Method (FEM). This method also can be used to extract parameters [10]. Equations (7) and (8) are used to calculate refractive index and impedance, from transmission coefficient $\left(S_{21}\right)$ and reflection coefficient $\left(S_{11}\right)$.

$$
Z_{\text {eff }}= \pm \sqrt{\frac{\left(1+S_{11}\right)^{2}-\left(S_{21}\right)^{2}}{\left(1-S_{11}\right)^{2}-\left(S_{21}\right)^{2}}}
$$

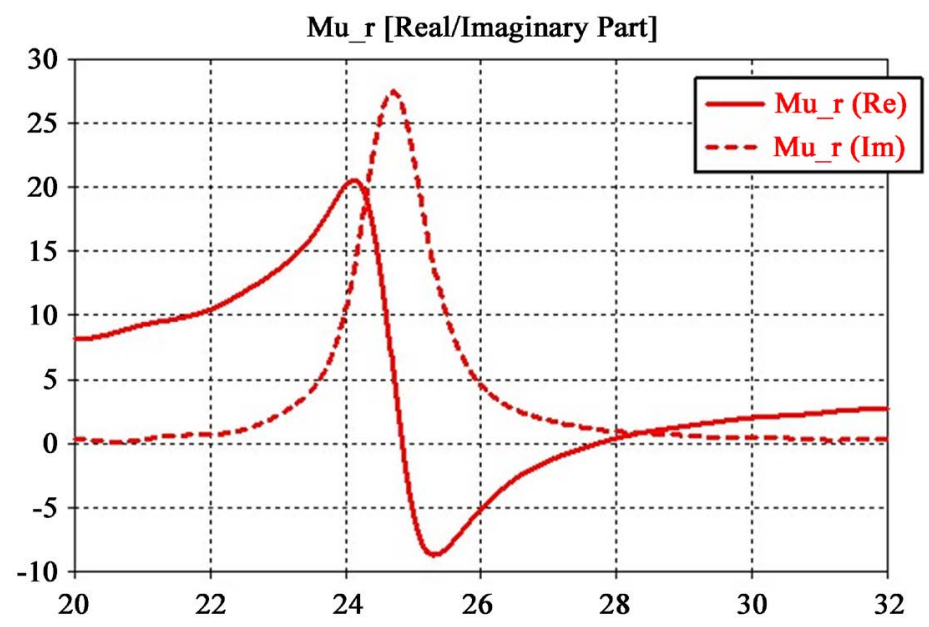

Figure 4. The real and imaginary part of Mu of SSRR at frequency $26 \mathrm{GHz}$. 


$$
\begin{gathered}
\eta_{\text {eff }}= \pm \frac{1}{k_{0} d}\left[\left\{\left[\operatorname{In}\left(e^{\text {inkod }}\right)\right]+2 m \pi\right\}-i\left[\operatorname{In}\left(e^{\text {inkod }}\right)\right]\right] \\
e^{\text {inkod }}=\frac{S_{21}}{1-S_{11}\left[\frac{(z-1)}{(z+1)}\right]}
\end{gathered}
$$

where $k_{0}$ is the wave vector in a vacuum, defined as $k_{0}=2 \pi / \omega_{o}, d$ is the thickness of the substrate, and $m$ is an integer. We can find $Z_{\text {eff }}$ and $N_{\text {eff }}$ from the above equation. Considering that metamaterial are passive media. That is a real part of the impedance is the positive and the imaginary part of the refractive index is negative. Further $\epsilon_{r, \text { eff }}$ and $\mu_{r, \text { eff }}$ can be obtained according to, $\epsilon_{r, e f f}=N_{\text {eff }} / Z_{\text {eff }}$ and $\mu_{r, e f f}=N_{e f f} Z_{\text {eff }}$

\section{Application of Metamaterial in Designing Edge Port Fed Rectangular Microstrip Patch Antenna}

Antennas are fabricated using DNG or SNG Metamaterial cells, which is used to increase the performance of the system. These cells could substantially increase the gain and radiated power of an antenna. Furthermore, these antennas can improve efficiency bandwidth performance. Various metamaterial-based antennas can be used for wireless communication, Cell phones, etc. [11]-[21].

\subsection{RMPA Design on Substrate without Metamaterial}

Rectangular microstrip patch antenna. (RMPA) design on RT Duroid substrate with edge port feed at resonance frequency $26 \mathrm{GHz}$ as employed in $5 \mathrm{G}$ communication and tested on software FEKO. The width of RMPA is given by Equation (9). Effective permittivity and fringing length delta $L$ are shown in Equations (10) and (11) respectively.

$$
\begin{gathered}
w=\frac{c_{0}}{2 f_{r}} \sqrt{\frac{2}{\varepsilon_{r}+1}} \\
\varepsilon_{\text {reff }}=\frac{\varepsilon_{r}+1}{2}+\frac{\varepsilon_{r}-1}{2}\left[1+12 \frac{h}{w}\right]^{-\frac{1}{2}} \\
\Delta L=h(0.412) \frac{\left(\varepsilon_{\text {reff }}+0.3\right)\left(\frac{w}{h}+0.264\right)}{\left(\varepsilon_{\text {reff }}-0.258\right)\left(\frac{w}{h}+0.264\right)}
\end{gathered}
$$

Effective length and actual length are given in Equations (12) and (13) Substrate length and width are given in Equations (14) and (15) respectively.

$$
\begin{gathered}
L_{e f f}=\frac{c_{0}}{2 f_{r} \sqrt{\varepsilon_{\text {reff }}}} \\
L=L_{\text {eff }}-2 \Delta L
\end{gathered}
$$

Substrate length $=L+6 h$ 
Substrate width $=w+6 h$.

$h=$ height of the substrate, $w=$ width of rectangular patch $L=$ Length of RMPA;

$c_{0}=$ Speed of electromagnetic wave [20].

\subsection{Edge Port Fed Rectangular Microstrip Patch Antenna (RMPA) Design on a Substrate without Metamaterial}

Figure 5 shows the design of Edge fed RMPA without metamaterial on RT duroid 5880 substrates. A Microstrip line is used for feeding the antenna.

Design of edge fed RMPA without metamaterials is shown in Table 1. Resonance freq. $=26 \mathrm{GHz}$, Substrate: $\mathrm{RT}$ Duroid 5880, $\varepsilon_{r}=2.2$, Loss tangent: 0.0009 , height of substrate $(h)=0.5 \mathrm{~mm}$.

Figure 6 shows the reflection coefficient v/s frequency graph of RMPA. At the resonance frequency, the return loss is very low $(-54 \mathrm{~dB})$, which means the maximum power is radiated by the antenna. Figure 7 Is a smith chart showing impedance matching of RMPA at $26 \mathrm{GHz}$. The impedance of the patch is zero at

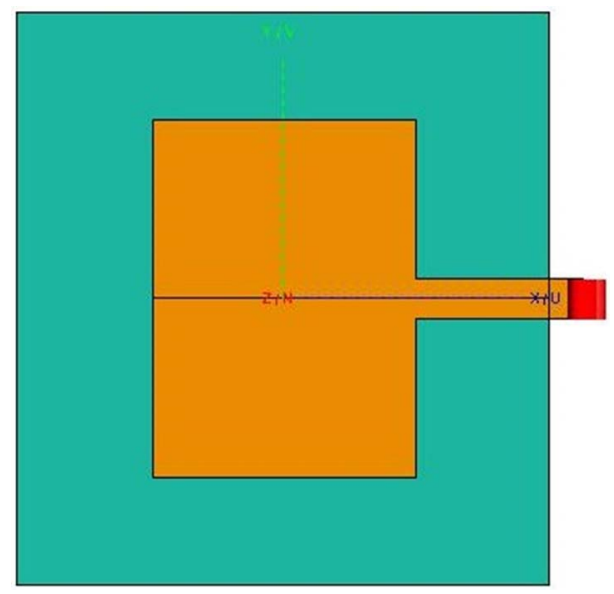

Figure 5. Design of RMPA without metamaterial.

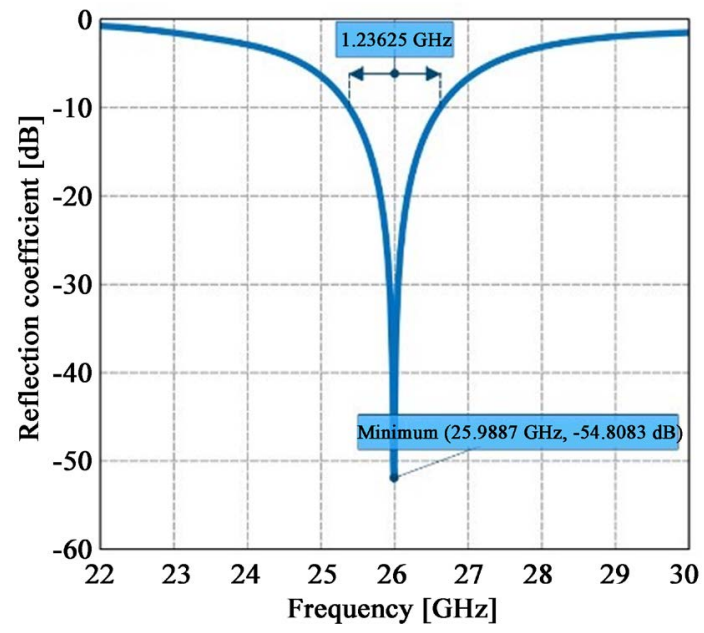

Figure 6. Reflection coefficient v/s freq of RMPA. 
Table 1. Design of edge-fed RMPA without metamaterial.

\begin{tabular}{ccc}
\hline & $\begin{array}{c}\text { Patch antenna calculated } \\
\text { dimensions }(\mathrm{mm})\end{array}$ & $\begin{array}{c}\text { Patch antenna optimized } \\
\text { imensions }(\mathrm{mm})\end{array}$ \\
\hline Width of the patch $(w)$ & 4.56 & 4.26 \\
Length of the patch $(L)$ & 3.57 & 3.25 \\
Sub.width $\left(W_{s}\right)$ & 7.56 & 7.0 \\
Sub.Length $\left(L_{s}\right)$ & 6.57 & 6.5 \\
Feed length $(a)$ & 1.63 & 1.63 \\
Feed width $(b)$ & 0.49 & 0.49 \\
\hline
\end{tabular}

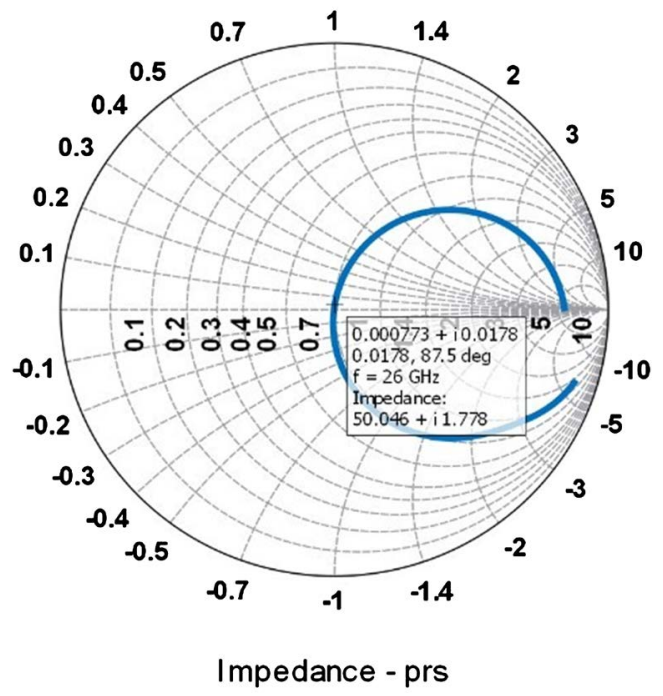

Figure 7. RMPA impedance matching at $26 \mathrm{GHz}$.

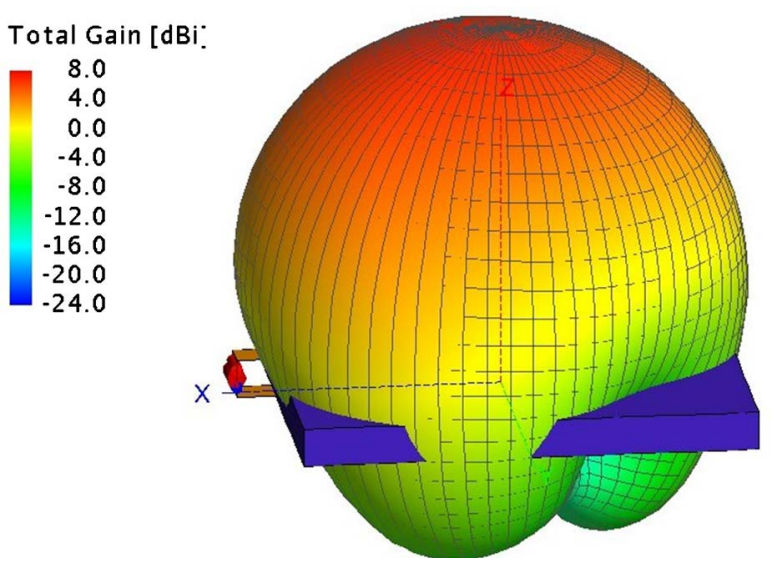

Figure 8. 3D view of far-field of an RMPA at $26 \mathrm{GHz}$.

the center and increases to words edges. If at the edges impedance is very high then a quarter-wave transformer should be used for impedance matching. Otherwise, a microstrip line will match the $50 \mathrm{ohms}$ port impedance. The reflection coefficient indicates the amount of electromagnetic wave is reflected by an impedance mismatch in the transmission medium. It is a ratio of the amplitude of 
the reflected wave to the wave incident at the junction. The reflection coefficient is denoted by the symbol gamma. The magnitude of the reflection cefi-cientdoes not depend on the length of the line, only the load impedance and the impedance of the transmission line. The reflection coefficient, commonly denoted by the Greek letter gamma $(\Gamma)$, can be calculated by using the formula $\Gamma=\left(Z_{l}-Z_{0}\right) /\left(Z_{l}+Z_{0}\right)$. Where $Z_{l}$ is complex load impedance and $Z_{0}$ transmission line characteristic impedance which in principle could also be a complex number. The square of $|\Gamma|$ is then the power of the reflected wave, Now we can define VSWR (SWR) as a scalar value: $\operatorname{VSWR}=(1+|\Gamma|) /(1-|\Gamma|)$ or in s-parameters: $\operatorname{VSWR}=\left(1+\left|S_{11}\right|\right) /\left(1-\left|S_{11}\right|\right)$.

The gain of an antenna is a very important parameter, gain should be very close to directivity so that the efficiency of the patch antenna increases. Figure 8 presents a 3D view of the far-field of an edge-fed patch antenna without metamaterial at $26 \mathrm{GHz}$. The total gain of the antenna also has been depicted in the figure.

\subsection{Edge Port fed Rectangular Microstrip Patch Antenna. (RMPA) Design with Metamaterial at $26 \mathrm{GHz}$ Resonating Frequency}

Figure 9 depicts the design of edge-fed RMPA with metamaterial cells on the ground plane of the antenna. Square split ring resonator (SSRR) cells are loaded in the ground plane of an antenna.

The optimized design of edge-fed microstrip patch antenna with metamaterial is shown in Table 2. The patch antenna is designed on RT Duroid 5880 substrate. Resonance freq. $=26 \mathrm{GHz}$, Substrate: RT Duroid 5880, $\varepsilon_{r}=2.2$, Loss tangent $=0.0009$, height of substrate $(h)=0.5 \mathrm{~mm}$.

Figure 10 shows the reflection coefficient v/s frequency graph of RMPA with metamaterial. At the resonance frequency, the return loss is very low $(-55 \mathrm{~dB})$, which means the maximum power is radiated by the antenna. Figure 11 is a Smith chart showing impedance matching of RMPA with metamaterial at 26 GHz. At $26 \mathrm{GHz}$ the impedance is almost $50 \mathrm{ohms}$ and reactive impedance is

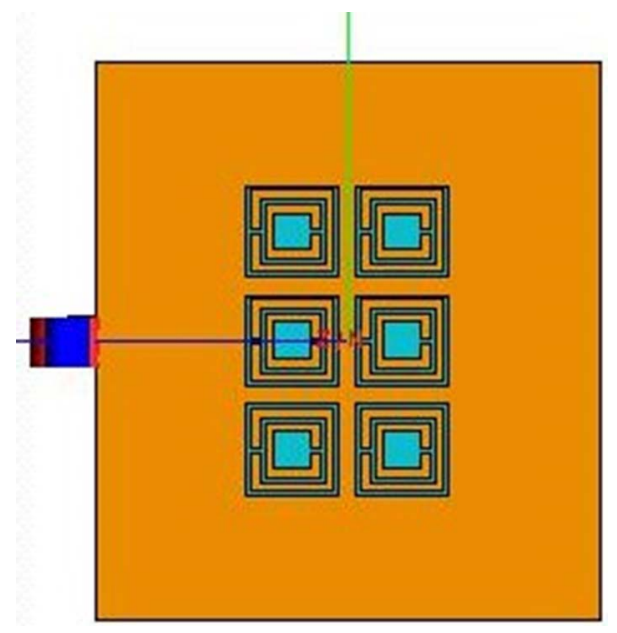

Figure 9. Design of metamaterial-loaded RMPA. 
Table 2. Design of Edge port fed RMPA with metamaterial.

\begin{tabular}{cc}
\hline & Optimized dimensions of patch antenna with slot $(\mathrm{mm})$ \\
\hline Width of the patch $(w)$ & 4.26 \\
Length of the patch $(L)$ & 2.9 \\
Sub.width $\left(W_{s}\right)$ & 6.5 \\
Sub.Length $\left(L_{s}\right)$ & 6 \\
Feed length $(a)$ & 1.55 \\
Feed width $(b)$ & 0.53 \\
\hline
\end{tabular}

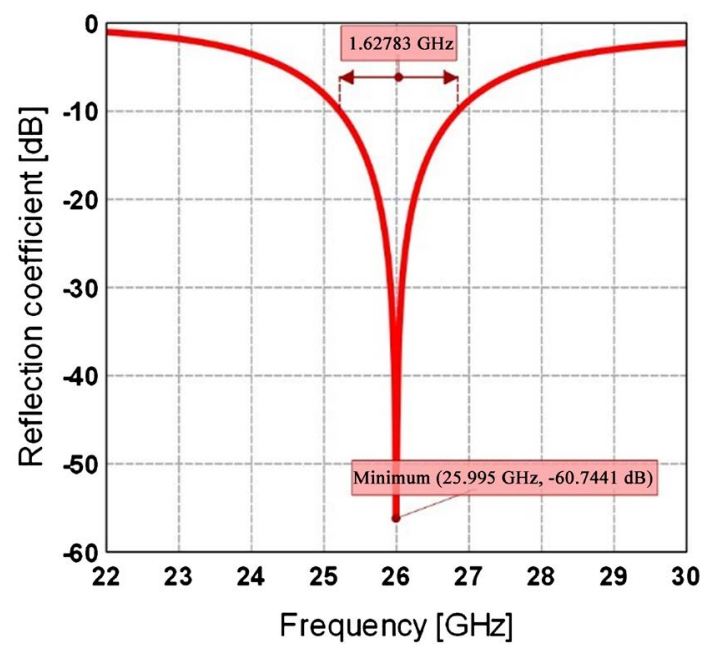

Figure 10. Shows reflection coefficient v/s frequency graph of RMPA with metamaterial.

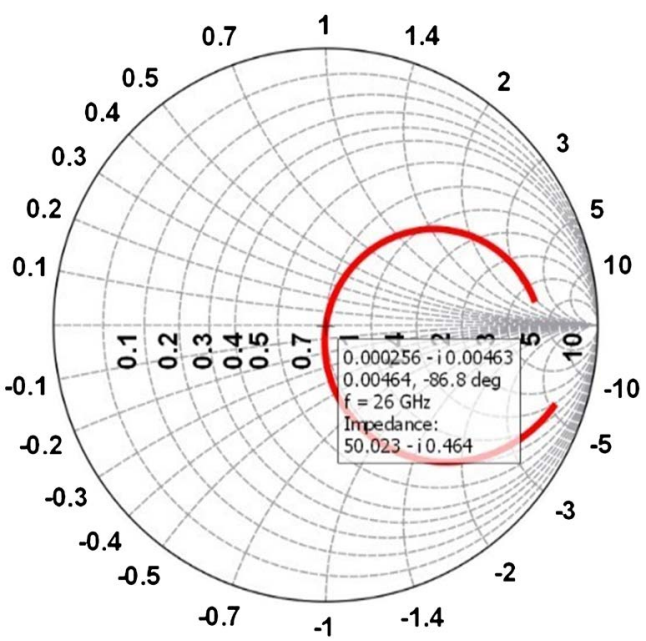

Figure 11. Smith chart showing impedance matching of RMPA with metamaterial.

almost zero, which matches with source impedance.

Figure 12(a) presents 3D view of the far-field of a RMPA at $26 \mathrm{GHz}$ resonance frequency. Figure 12(b) presents 3D view of the far-field of a RMPA at 25 $\mathrm{GHz}$ frequency and Figure 12(c) presents 3D view of the far-field of a RMPA at $27 \mathrm{GHz}$ frequency. The gain of the antenna is $10 \mathrm{dBi}$ at $8 \mathrm{dBi}$ and $9 \mathrm{dBi}$ at 26 


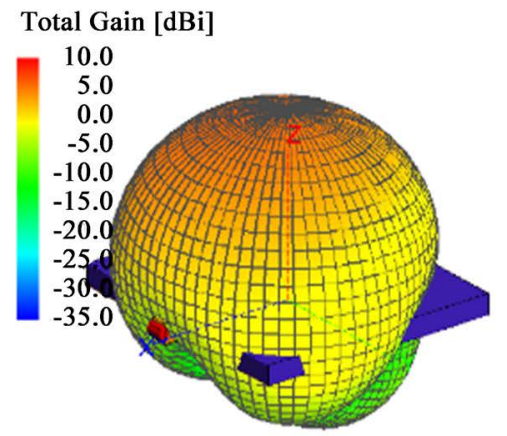

(a)

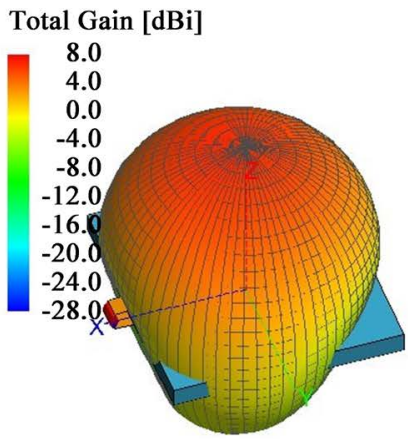

(b)

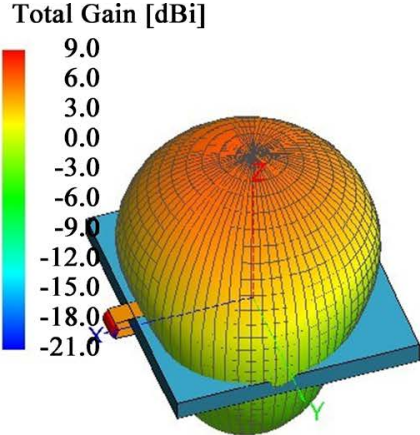

(c)

Figure 12. (a) 3D view of the far-field of an RMPA at $26 \mathrm{GHz}$ resonance frequency; (b) 3D view of the far-field of an RMPA at $25 \mathrm{GHz}$ frequency; (c) 3D view of the far-field of an RMPA at $27 \mathrm{GHz}$ frequency.

$\mathrm{GHz}, 25 \mathrm{GHz}$ and $27 \mathrm{GHz}$ respectively.

\section{Application of Metamaterial in Designing Edge Port Fed Circular Microstrip Patch Antenna (CMPA).}

Circular microstrip patch Antennas are designed using DNG or SNG Metamaterial cells, which is used to increase the performance of the system. These cells could substantially increase the gain and radiated power of an antenna. Furthermore, these antennas can improve efficiency-bandwidth performance. Various metamaterial-based antennas can be used for wireless communication [21] [22].

\subsection{CMPA Design on Substrate without Metamaterial}

Circular microstrip patch antenna (CMPA) design on RT Duroid substrate with edge port feed at resonance frequency $26 \mathrm{GHz}$ as employed in $5 \mathrm{G}$ communication and tested on software FEKO. The radius of the circular patch of CMPA is given by Equation (15). Where $r$ is the actual radius and $F$ is the effective radius of the circular patch, $h$ is the height of the substrate.

$$
\begin{gathered}
r=\frac{F}{\left\{1+\frac{2 h}{\pi \varepsilon_{r}}\left[\operatorname{In}\left(\frac{\pi F}{2 h}\right)+1.7726\right]\right\}^{\frac{1}{2}}} \\
F=\frac{8.79 \times 10^{9}}{f_{r} \sqrt{\varepsilon_{r}}}(h \text { is in cms }) .
\end{gathered}
$$

\subsection{Edge Port fed Circular Microstrip Patch Antenna (CMPA) Design on a Substrate without Metamaterial}

Figure 13 shows the design of Edge fed CMPA without metamaterial on RT duroid 5880 substrates.

Design of edge fed CMPA without metamaterials is shown in Table 3. Resonance freq. $=26 \mathrm{GHz}$, Substrate: RT Duroid 5880, $\varepsilon_{r}=2.2$, Loss tangent $=$ 0.0009 , hight of substrate $(h)=0.5 \mathrm{~mm}$. 
Figure 14 shows the reflection coefficient v/s frequency graph of CMPA. The return loss at resonance frequency is very low $(-56 \mathrm{~dB})$, which means the maximum power is radiated by the antenna. Figure 15 Is a smith chart showing impedance matching of RMPA at $26 \mathrm{GHz}$. The impedance of the patch is zero at the center and increases to words edges. If at the edges impedance is very high then a quarter-wave transformer should be used for impedance matching. Otherwise, a microstrip line will match the $50 \mathrm{ohms}$ port impedance. The graph of VSWR v/s frequency is presented in Figure 16. VSWR of CMPA is 1.0 at $26 \mathrm{GHz}$. VSWR (voltage standing wave ratio) is the measure of RF power is transmitted into a load. We would like to cite one example, power amplifier is connected to

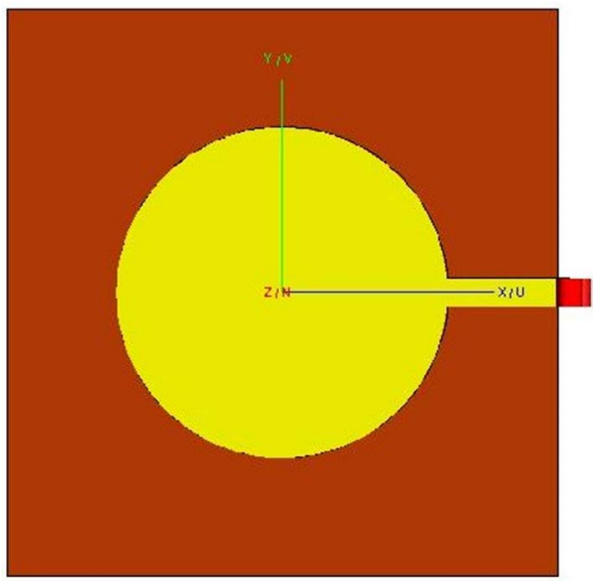

Figure 13. Design of edge-fed CMPA.

Table 3. Design of edge-fed CMPA without metamaterial.

\begin{tabular}{lcc}
\hline & $\begin{array}{c}\text { Patch antenna calculated } \\
\text { dimensions }(\mathrm{mm})\end{array}$ & $\begin{array}{c}\text { Patch antenna optimized } \\
\text { imensions }(\mathrm{mm})\end{array}$ \\
\hline Radius of patch & 2.2 & 2.10 \\
Sub.width $\left(W_{s}\right)$ & 7.4 & 7.2 \\
Sub.Length $\left(L_{s}\right)$ & 7.4 & 7 \\
Feed length $(a)$ & 1.4 & 1.4 \\
Feed width $(b)$ & 0.36 & 0.36 \\
\hline
\end{tabular}

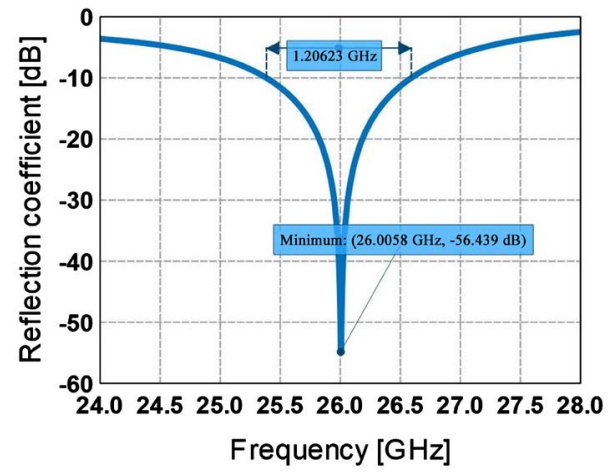

Figure 14. Reflection coefficient v/s frequency of Edge fed CMPA. 
an antenna through a transmission line ideally, there will be no reflections and full signal from the power amplifier will be transmitted to the antenna. However in this world, no system is ideal, there will be some mismatches which will cause some of the signal to get reflected back into the transmission line. If VSWR is one that means the system is perfectly matched.

The gain of an antenna is a very important parameter, gain should be very close to directivity so that the efficiency of the patch antenna increases. Figure 17

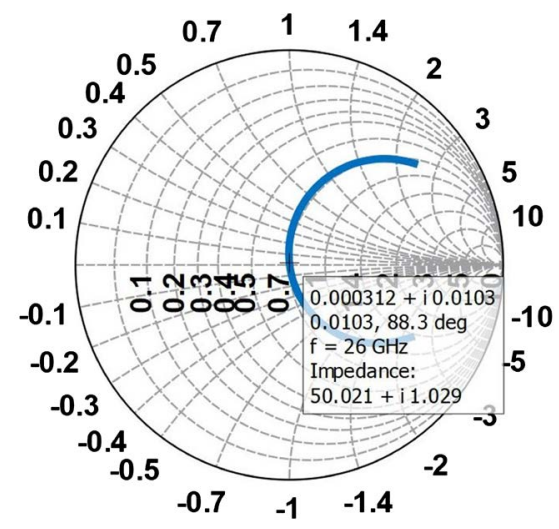

Figure 15. Smith chart showing impedance matching at $26 \mathrm{GHz}$.

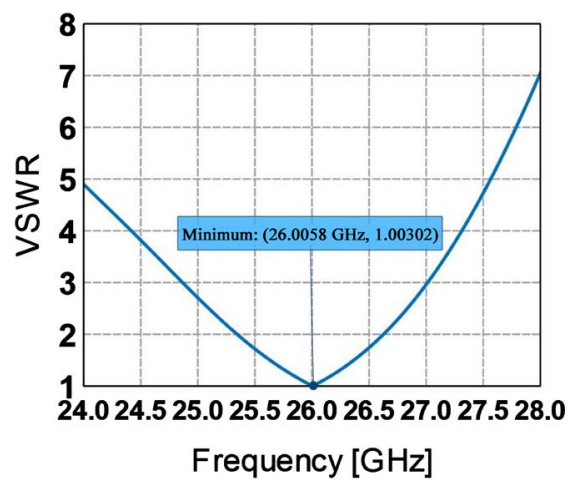

Figure 16. VSWR v/s Frequency of CMPA with metamaterial. at $26 \mathrm{GHz}$.

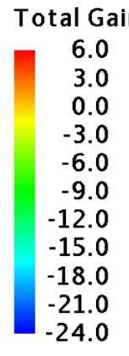

(a)

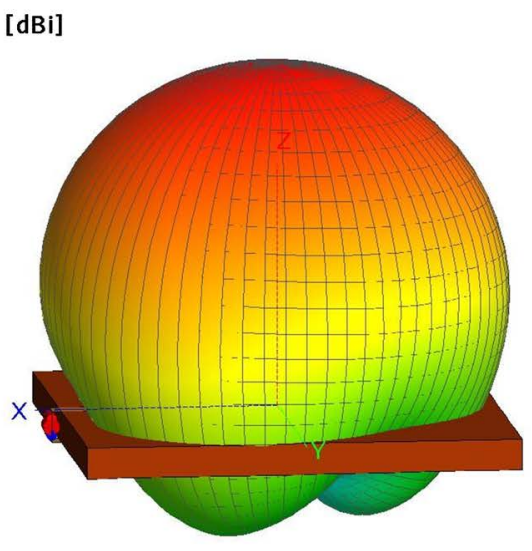

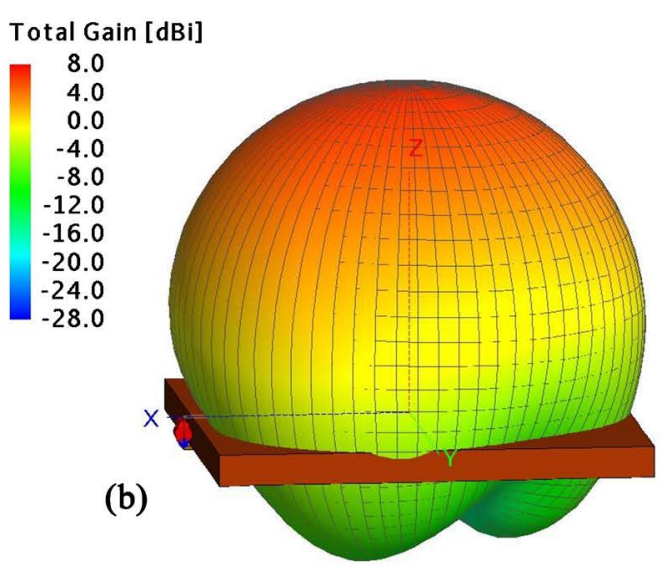

Figure 17. (a) 3D view of the far-field of a CMPA at $25 \mathrm{GHz}$ resonance frequency; (b) $3 \mathrm{D}$ view of the far-field of a CMPA at $26 \mathrm{GHz}$ frequency. 
presents a 3D view of the far-field of an edge-fed patch antenna without metamaterial at $26 \mathrm{GHz}$. The total gain of an antenna also has been depicted in the figure. The gain is $8 \mathrm{dBi}$ and $6 \mathrm{dBi}$ at $26 \mathrm{GHz}$ and $25 \mathrm{GHz}$ respectively.

\subsection{Edge Port Fed Circular Microstrip Patch Antenna. (CMPA) Design with Metamaterial at $26 \mathrm{GHz}$ Resonating Frequency}

Figure 18 depicts the design of edge-fed CMPA with metamaterial cells on the ground plane of the antenna. Mu metamaterial cells are loaded on the ground plane of the antenna.

The optimized design of edge-fed microstrip patch antenna with metamaterial is shown in Table 4. The patch antenna is designed on RT Duroid substrate. Resonance freq. $=26 \mathrm{GHz}$, Substrate: RT Duroid 5880, $\varepsilon_{r}=2.2$, Loss tangent $=$ 0.0009 , height of substrate $(h)=0.5 \mathrm{~mm}$.

Figure 19 shows the reflection coefficient v/s frequency graph of CMPA with metamaterial. At the resonance frequency, the return loss is very low $(-43 \mathrm{~dB})$, which means the maximum power is radiated by the antenna. Figure 20 is a Smith chart showing impedance matching of CMPA with metamaterial at 26 GHz. At $26 \mathrm{GHz}$ the impedance is almost $50 \mathrm{ohms}$, which matches with source impedance. Figure 21 shows the graph of VSWR v/s Frequency. The value of VSWR is 1.0 .

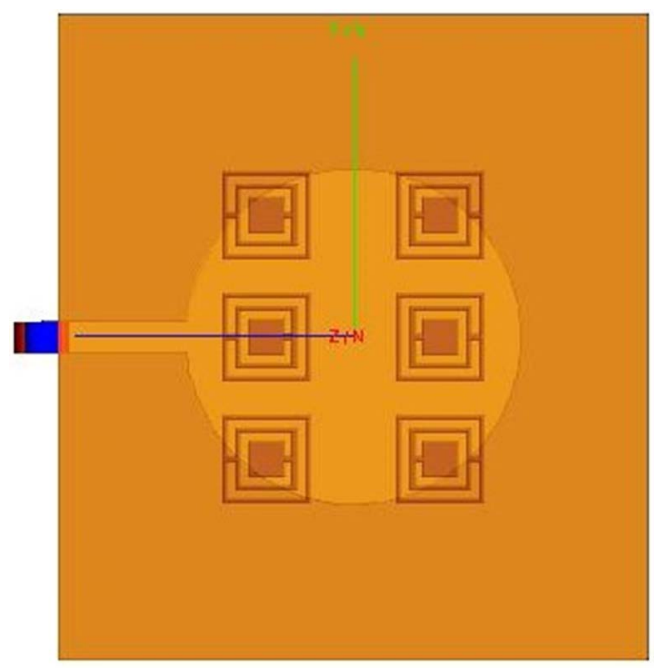

Figure 18. Design of metamaterial-loaded RMPA.

Table 4. Design of edge port fed CMPA with metamaterial.

\begin{tabular}{lc}
\hline & Optimized dimensions of patch antenna with slot $(\mathrm{mm})$ \\
\hline Radius of patch & 1.92 \\
Sub.width $\left(W_{s}\right)$ & 7.4 \\
Sub.Length $\left(L_{s}\right)$ & 6.75 \\
Feed length $(a)$ & 1.45 \\
Feed width $(b)$ & 0.34 \\
\hline
\end{tabular}




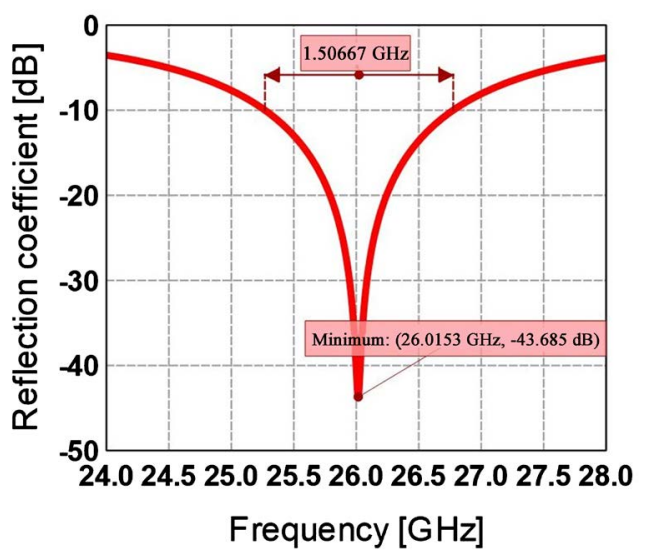

Figure 19. Shows reflection coefficient v/s frequency graph of RMPA with metamaterial.

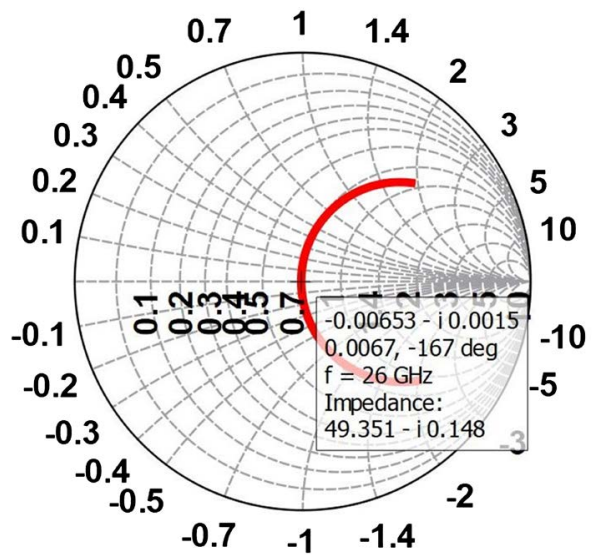

Figure 20. Smith chart showing impedance matching of CMPA with metamaterial.

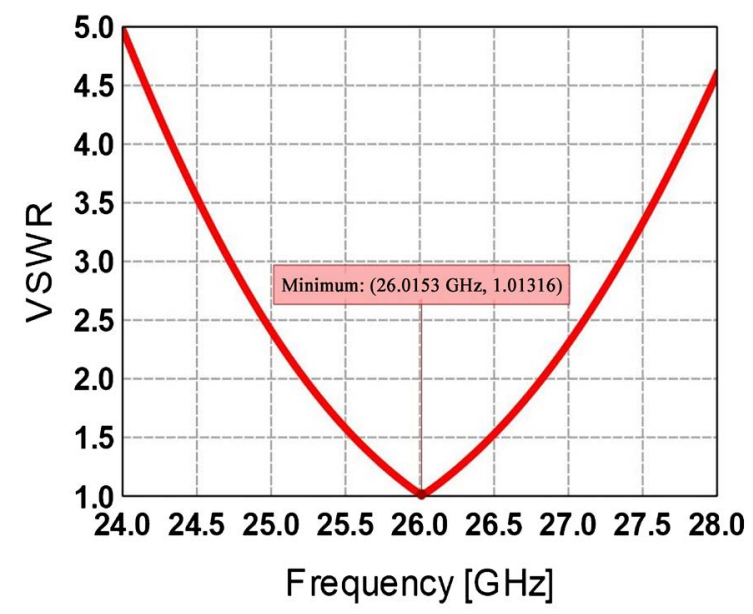

Figure 21. VSWR v/s frequency of CMPA with metamaterial.

A Figure 22(a) depicts the 3D view of the far-field of a CMPA at $26 \mathrm{GHz}$ resonance frequency. Figure 22(b) is a 3D view of the far-field of a CMPA at 25 $\mathrm{GHz}$ frequency. Figure 22(c) shows 3D view of a Theta gain of a CMPA at 26 $\mathrm{GHz}$ frequency. It is a gain at theta equal to zero and phi equal to 90 degrees and Figure 22(d) shows the Directivity of an antenna at $26 \mathrm{GHz}$. 

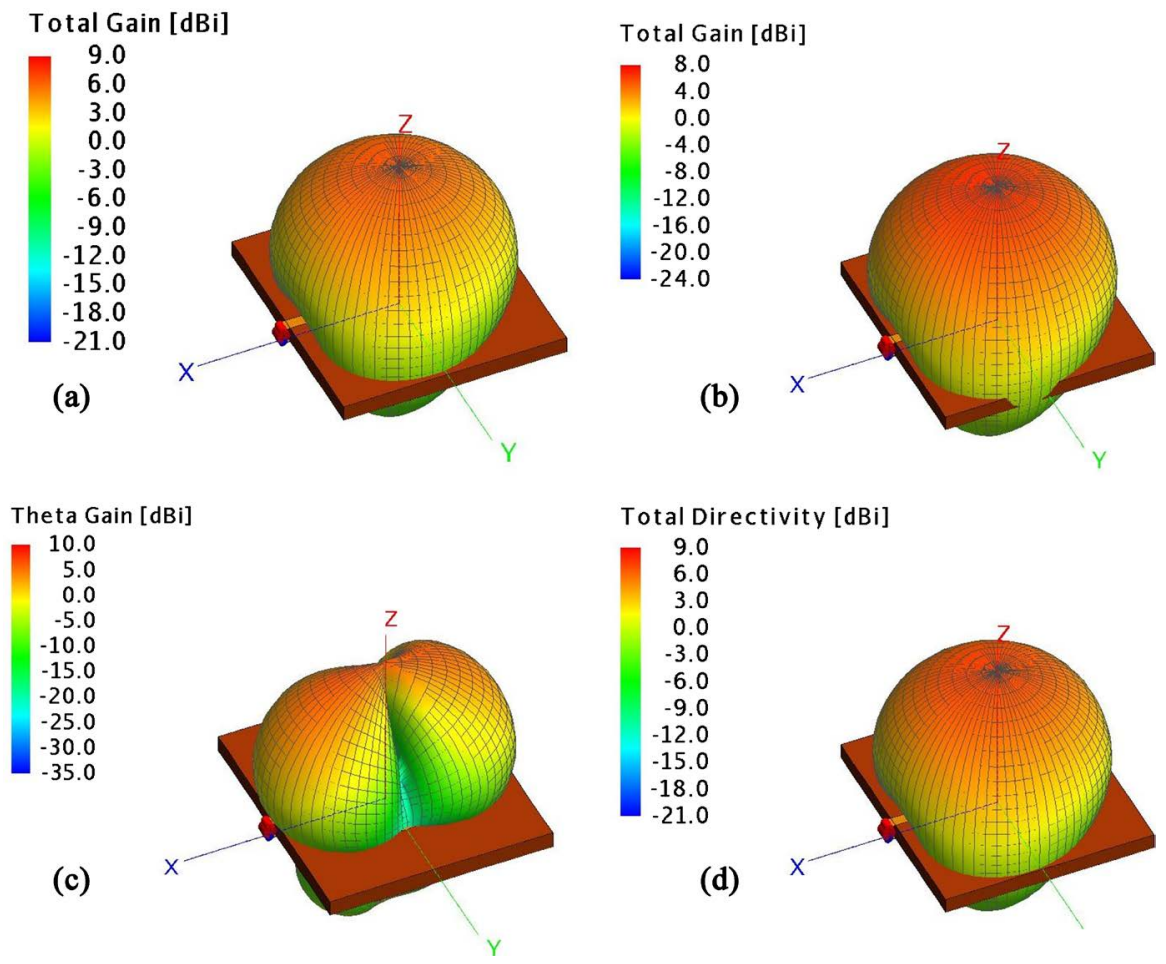

Figure 22. (a) $3 \mathrm{D}$ view of the far-field of a CMPA at $26 \mathrm{GHz}$ resonance frequency; (b) $3 \mathrm{D}$ view of the far-field of a CMPA at $25 \mathrm{GHz}$ frequency; (c) 3D view of Theta gain of of a CMPA at $26 \mathrm{GHz}$ frequency; (d) Directivity of antenna.

\section{Simulation Results}

The metamaterial cell comprising of SSRR is designed and simulated using MATLAB and CST software, it has been found that the cell with SSRR is a single or mu negative cell that shows negative permeability. The comparison of the parameters of RMPA with and without metamaterial is listed in Table 5. And the comparison of the parameter of Conventional edge fed CMPA and CMPA loaded with metamaterial is listed in Table 6 . Both the antennas with metamaterial cells on the ground plane are designed and simulated using FEKO, It has been observed that the gain and bandwidth of patch antenna increases in comparison to RMPA without metamaterial.

RMPA loaded with and without metamaterial are simulated using FEKO, It has been found that the bandwidth of antenna loaded with metamaterial cells increases considerably in comparison to RMPA without cells. RMPA without cells returns loss and bandwidth are $-54 \mathrm{~dB} \& 1.23 \mathrm{GHz}$ respectively. Whereas RMPA with metamaterial the values of Return loss and bandwidth are $-60.7 \mathrm{~dB}$ \& $1.62 \mathrm{GHz}$ respectively. Gain of RMPA without and with cells is found to be equal to $8 \mathrm{dBi}$ and $10 \mathrm{dBi}$ respectively. So the bandwidth is increased by 400 $\mathrm{MHz}$. And gain is increased by $2 \mathrm{dBi}$ based on simulated results it has been found that the bandwidth and gain of RMPA have improved. VSWR of the conventional antenna is 1.1 and that of the antenna with metamaterial is 1.02 Smaller the value better is impedance matching. The lowest value of VSWR for 
Table 5. Different parameters of RMPA.

\begin{tabular}{ccc}
\hline \multicolumn{3}{c}{ Parameters of RMPA } \\
\hline & RMPA without metamaterial & RMPA with metamaterial \\
\hline Reflection coefficient & $-54 \mathrm{~dB}$ & $-60.7 \mathrm{~dB}$ \\
Bandwidth $(10 \mathrm{db})$ & $1.23 \mathrm{GHz}$ & $1.62 \mathrm{GHz}$ \\
Gain & $8 \mathrm{dBi}$ & $10 \mathrm{dBi}$ \\
VSWR & 1.1 & 1.04 \\
\hline
\end{tabular}

Table 6. Different parameters of CMPA.

\begin{tabular}{ccc}
\hline \multicolumn{3}{c}{ Parameters of CMPA } \\
\hline & CMPA without metamaterial & CMPA with metamaterial \\
\hline Reflection coefficient & $-56 \mathrm{~dB}$ & $-43.6 \mathrm{~dB}$ \\
Bandwidth $(10 \mathrm{db})$ & $1.20 \mathrm{GHz}$ & $1.50 \mathrm{GHz}$ \\
Gain & $8 \mathrm{dBi}$ & $9 \mathrm{dBi}$ \\
VSWR & 1.00 & 1.01 \\
\hline
\end{tabular}

ideal antenna is equal to one. Conventional CMPA metamaterial loaded CMPA are simulated using FEKO, It has been found that the bandwidth of antenna loaded with metamaterial cells increases considerably in comparison to CMPA without cells. CMPA without cells returns loss and bandwidth are $-56 \mathrm{~dB} \& 1.20$ $\mathrm{GHz}$ respectively. Whereas CMPA with metamaterial the values of Return loss and bandwidth are $-43.6 \mathrm{~dB} \& 1.50 \mathrm{GHz}$ respectively. Gain of CMPA without and with cells is found to be equal to $8 \mathrm{dBi}$ and $9 \mathrm{dBi}$ respectively. So the bandwidth is increased by $300 \mathrm{MHz}$. And gain is increased by $1 \mathrm{dBi}$ based on simulated results it has been found that the bandwidth and gain of CMPA have improved. VSWR of the conventional antenna is 1.0 and that of the antenna with metamaterial is 1.01 .

\section{Conclusion}

This paper presents an edge port fed rectangular microstrip patch antenna and Circular patch antenna without and with metamaterial. Design and simulated results indicate that the RMPA gain and bandwidth have improved considerably by loading metamaterial on it. The simulated result shows $50 \mathrm{ohms}$ impedance matching at $26 \mathrm{GHz}$. Also, the dimensions of the patch antenna have been decreased. The bandwidth and gain of RMPA are considerably higher compared to CMPA.

\section{Conflicts of Interest}

The authors declare no conflicts of interest regarding the publication of this paper. 


\section{References}

[1] Hamad, E.K.I. and Abdelaziz, A. (2019) Metamaterial Superstrate Microstrip Patch Antenna for $5 \mathrm{G}$ Wireless Communication Based on the Theory of Characteristic Modes. Journal of Electrical Engineering, 70, 187-197. https://doi.org/10.2478/jee-2019-0027

[2] Przesmycki, R., Bugaj, M. and Nowosielski, L. (2020) Broadband Microstrip Antenna for 5G Wireless Systems Operating at 28 GHz. Electronics, 10, 1-19. https://doi.org/10.3390/electronics10010001

[3] Liu, Y.h., Guo, X.j., Gu, S. and Zhao, x.p. (2013) Zero Index Metamaterial for Designing High-Gain Patch Antenna. International Journal of Antennas and Propagation, 2013, Article ID: 215681. https://doi.org/10.1155/2013/215681

[4] Marques, R., Mesa, F., Martel, J. and Median, F. (2003) Comparative Analysis of Edge and Broadside Coupled Split-Ring Resonators for Metamaterial Design-Theory and Experiment. IEEE Transactions on Antennas and Propagation, 51, 2572-2581. https://doi.org/10.1109/TAP.2003.817562

[5] Joshi, J.G., Pattnaik, S.S. and Devi, S. (2012) Article Metamaterial Embedded Wearable Rectangular Microstrip Patch Antenna. International Journal of Antennas and Propagation, 2012, Article ID: 974315. https://doi.org/10.1155/2012/974315

[6] Tarpara, N.M., Rathwa, R.R. and Kotak, N.A. (2018) Design of Slotted Microstrip Patch Antenna for 5G Application. International Research Journal of Engineering and Technology (IRJET), 5, 2827-2832.

[7] Liu, Y.m. and Zhang, X. (2011) Metamaterials: A New Frontier of Science and Technology. Chemical Society Reviews, 40, 2494-2507. https://doi.org/10.1039/c0cs00184h

[8] Eader, N., Richard, E. and Ziolkowski, W. (2006) Metamaterials: Physics and Engineering Explorations. John Wiley \& Sons, Inc., USA.

[9] Hassan, N. (2021) MATLAB to CST Interfacing Method Tutorial.

[10] Numan, A.B. and Sharawi, M.S. (2013) Extraction of Material for Metamaterials using a Full Wave Simulator. IEEE Antenna and Propagation, 55, 202-211. https://doi.org/10.1109/MAP.2013.6735515

[11] Chandan, R.S., Deepthi, P.S., Teja, D.S., Krishna, J. and Sujata, M. (2018) Design of Single-Band Microstrip patch Antenna for 5G Application. International Journal of Engineering and Technology, 7, 2-7. https://doi.org/10.14419/ijet.v7i2.7.10877

[12] Yang, F., Zhang, X., Ye, X. and Rahmat-Samii, Y. (2001) Wideband E-shaped patch Antennas for Wireless Communications. IEEE Transactions on Antennas and Propagation, 49, 1094-1100. https://doi.org/10.1109/8.933489

[13] Sing, A.P., Kumar, R. and Dadhwal, H.S. (2012) Design of Edge Fed Rectangular Microstrip Ring Antenna for WLAN Application Using Ansoft-HFSS. VSRD-IJEECE, 2, 160-167.

[14] Garg, R. and Reddy, V.S. (2003) Edge Feeding of Microstrip Ring Antenna. IEEE transaction on Antennas and propagation, 51, 1941-1946. https://doi.org/10.1109/TAP.2003.815423

[15] Ge, Y., Estelle, K. and Bird, T. (2004) E-Shaped Patch Antennas for High-Speed Wireless Networks. IEEE Transactions on Antennas and Propagation, 52, 3213-3219. https://doi.org/10.1109/TAP.2004.836412

[16] Kamal, S., Islam, J., Uddin, J. and Imran, A.Z.M. (2018) Design of a Tri-band Microstrip Patch Antenna for 5G Application. 2018 International Conference on Computer, Communication, Chemical, Material and Electronic Engineering (ICAME2), 
Rajshahi, Bangladesh, 8-9 February 2018.

https://doi.org/10.1109/IC4ME2.2018.8465627

[17] Sarade, S.S., Ruikar, S.D. and Bhaldar, H.K. (2020) Design of Microstrip Patch Antenna for 5G Application. In: Pawar, P., Ronge, B., Balasubramaniam, R., Vibhute, A., Apte, S., Eds., Techno-Societal 2018, Springer, Cham.

https://doi.org/10.1007/978-3-030-16848-3_24

[18] Satarkar, P.R. and Lohani, R.B. (2020) Design and Characterization of Coaxial Feed Circular Patch Antenna on a Metamaterial Substrate. 2020 Fourth World Conference on Smart Trends in Systems, Security and Sustainability (WorldS4), London, UK, 27-28 July 2020, 424-427. https://doi.org/10.1109/WorldS450073.2020.9210420

[19] Colaco, J. and Lohani, R. (2020) Design and Implementation of Microstrip Patch Antenna for 5G applications. 2020 International Conference on Communication and Electronics Systems (ICCES), Istanbul, Turkey, 12-13 June 2020, 682-685.

https://doi.org/10.1109/ICECCE49384.2020.9179263

[20] Gaitonde, J. and Lohani, R.B. (2020) GaAs OPFET for 5G applications. Proceedings of AICTE sponsored International Virtual Conference on Antenna Innovations, $5 G$ Communications and Network Technologies (ICA5NT 2020), Panchetti, India, 6-7 November 2020, 1-20.

[21] Balanis, C.A. (2005) Antenna Theory. 3rd Edition, John Wiley \& Sons, New Jersey.

[22] Şeker, C. and Güneşer, M.T. (2019) Design and Simulation of $26 \mathrm{GHz}$ Patch Antenna for 5G Mobile handset. 2019 11 th International Conference on Electrical and Electronics Engineering (ELECO), Bursa, Turkey, 28-30 November 2019, 382-386. https://doi.org/10.23919/ELECO47770.2019.8990634 